\title{
FUNCTIONAL EFFICIENCY OF ATHLETES IN MIDDLE DISTANCE RUNNING
}

\author{
Ivaylo Lazarov
}

National Sports Academy „Vassil Levski”, Sofia, Bulgaria

\begin{abstract}
Modern athletics is developing with incredible dynamics. In sports science and practice there are a number of proven methodological approaches that are related to the diagnosis of the training effects. One of the tasks of functional diagnostics in sports is researching and tracing the body changes related to energy supply in a certain training activity.

The aim of the research is to increase the effectiveness of the mid-distance training exercise through the creation of criteria for assessing the adaptation effects of the workloads. The subject of the study is the adaptation changes in the level of $\mathrm{HR}, \mathrm{VO}_{2}$ max and La in the conditions of the training activity. The research was done among 27 male middle distance competitors. The test was performed on the athletics track with the use of a special K4 set which recorded the pulse frequency and oxygen consumption dynamics. The concentration of lactate in capillary blood was recorded immediately after the run.

The results show that the speed of recovery of the pulse frequency in the phases of the shortened rest is the correct adaptation marker for the determination of the individual tolerance in running loads and the level of athletes' training.

The recommended quantitative values of the respiratory and metabolic adaptation markers and their associated running speed are as follows: aerobic threshold - 2 mmol/l at a running speed of less than $4.10 \mathrm{~m} / \mathrm{sec}$. and a heart rate up to $157 \mathrm{HR}$.; anaerobic threshold $-4 \mathrm{mmol} / \mathrm{l}$ at a running speed between 4.10 and $5.13 \mathrm{~m} / \mathrm{s}$ and a pulse limit of 157-178 HR - an effective aerobic zone (economic zone); over $178 \mathrm{HR}$ and the running speed over $5.13 \mathrm{~m} / \mathrm{s}$.
\end{abstract}

\section{INTRODUCTION}

Modern athletics is developing with incredible dynamics. In sports science and practice there are a number of proven methodological approaches that are related to the diagnosis of the training effects (Bonov, 2003; Dasheva, 2002; Dick, 2002; Furnadjiev, 2005; Neikov, 2017). A lot of authors constantly try to establish standards in training exercises (Bonov, 2003; Neikov, Dasheva, 2017; Lazarov, 1978). These are largely determined by the individual structure of competitors' adaptive potential. In this sense, finding objective methods for assessment of the effects of the applied workloads can alleviate coaches' work and prevent them from making inadequate decisions.

One of the tasks of functional diagnostics in sports is researching and tracing the body changes related to energy supply in a certain training activity. While the cardiovascular and respiratory systems transport oxygen and nutrients to the working muscles, the metabolic processes provide the energy required for their functioning. Therefore, the changes in the concentration of metabolites related to the energysupplying processes of the muscular work are of great value for the assessment of physical capacity. Lactic acid is such a metabolic and it is given special attention in the modern functional diagnostics (Astrand, 1986; Bauckaert, 
1999; Grancharov, 1997).

The rise in blood lactate concentration is an indicator of a change in the nature of the energy supply of muscle work - from aerobic to anaerobic. If the changes in lactic acid concentration in arterial blood coincide with those of ventilation, there is optimal breathing effectiveness, defined as ,Threshold of Anaerobic Exchange". One of the major aims of modern training methodology improvement is determining the anaerobic threshold and this is in the basis of all sports-functional diagnostic tests (Bauckaert, 1999; Grancharov, 1997).

Such complex studies of cardiovascular system activity and metabolic reactions to physical exercise have been made only in laboratory conditions. The conducted study allows to compare the results of the laboratory and field research and thus to improve the regulatory systems for control and evaluation of the adaptation processes that characterize the effectiveness of the training process (Mirzaei, Shadmehr, 2016).

The aim of the research is to increase the effectiveness of the mid-distance training exercise through the creation of criteria for assessing the adaptation effects of the workloads.

In order to fulfill the aim of the research we set the following tasks:

1. To explore athletes' functional capabilities in mid-distance running;

2. To analyze the changes in heart rate, VO$2 \mathrm{max}$ and $\mathrm{La}$ at intervals with progressive increase of intensity;

3. To establish adaptation markers quantitative values of respiratory and metabolic activities.

\section{METHODOLOGY}

We studied the adaptation changes in the level of $\mathrm{HR}, \mathrm{VO}_{2}$ max and $\mathrm{La}$ in the conditions of the training activity. The research was done among 27 male middle distance competitors with results in $800 \mathrm{~m}$ from $1: 47.14$ to $1: 54.75$ min. The testing was done during training sessions: 5 x 1000 meter load over a 3-minute passive pause with progressive time reduction (speed increasing) for each segment as follows: 1 - 4:00 $\mathrm{min}(4.17 \mathrm{~m} / \mathrm{s}), 2$ - 3:40 $\mathrm{min}$ $(4.54 \mathrm{~m} / \mathrm{s}), 3-3: 15 \min (5.13 \mathrm{~m} / \mathrm{s}), 4-3.00$ $\min (5.55 \mathrm{~m} / \mathrm{s}), 5-2: 50 \min (5.88 \mathrm{~m} / \mathrm{s})$. The test was performed on a standard running track $(400 \mathrm{~m})$. The pace of the running was regulated with a special automatic pacemaker. A telemetry computer equipment „K4” was used to measure the following indicators of activity of the cardiorespiratory system:

- Dynamics of the pulse frequency in the phases of load and rest;

- Dynamics of oxygen consumption (maximum and relative) in the operating and recovery phases

In addition, the lactate concentration in capillary blood was measured as follows:

- For the first minute after completion of the running from the inner clamshell - a lactate analyzer that automatically reports the lactate content was used;

- After the last blood test the procedure was repeated for 6 and 12 minutes, taking into account the current elimination time (immediate recovery)

\section{RESULTS AND ANALYSIS}

The middle-distance running is characterized by extremely high demands on all systems in an athlete's body. The 800 and $1500 \mathrm{~m}$ competitors reach $100 \%$ of their current aerobic power. Table 1 shows the results from the variance analysis of the researched functional marks and Table 2 - the correlations between marks, which confirms the thesis. At the same time, although the body works at similar level, the amount of oxygen that the systems provide is inadequate and the body falls into a state of deep acidosis. Trainings that develop resistance to such conditions require precise deter- 
mination of the critical levels in the work of cardio respiratory system.

the body's main systems, and in particular the

Table 1. Variance analysis of functional mark: $\mathrm{VO}_{2}$ max-maximum oxygen consumption, $\mathrm{VVO}_{2}$ max-speed of running in maximum oxygen consumption, vAnT-speed of anaerobic threshold, vAeT- speed of aerobic threshold, htrVO $\mathrm{O}_{2}$ ax-heart rate in maximum oxygen consumption, htrAnT-heart rate in threshold of anaerobic possibilities

\begin{tabular}{cccccccccc}
\hline $\mathbf{N}=\mathbf{2 7}$ & $\mathbf{n}$ & $\mathbf{X}_{\min }$ & $\mathbf{X}_{\max }$ & $\mathbf{R}$ & $\mathbf{X}$ & $\mathbf{S}$ & $\mathbf{V}$ & $\mathbf{A s}$ & $\mathbf{E x}$ \\
\hline $\mathbf{V O}_{2 \max }$ & 27 & 59.6 & 77.8 & 18.2 & 67.2 & 4.31 & 7.7 & 1.89 & 0.67 \\
$\mathbf{v V O}_{2 \max }$ & 27 & 4.2 & 5.9 & 1.7 & 5.12 & 0.53 & 10.7 & -0.93 & 0.12 \\
$\mathbf{v A n T}$ & 27 & 3.52 & 4.85 & 1.33 & 4.22 & 0.34 & 4.17 & -0.67 & 0.31 \\
vAeT & 27 & 3.69 & 4.52 & 0.83 & 4.12 & 0.18 & 5.78 & 2.31 & 1.76 \\
vrdst & 27 & 4.3 & 6.8 & 2.5 & 5.7 & 0.55 & 10.2 & 1.92 & -0.61 \\
htrVo2max & 27 & 186 & 212 & 26 & 200 & 5.87 & 2.98 & 0.65 & 0.91 \\
htrAnT & 27 & 172 & 197 & 25 & 187 & 7.86 & 4.08 & 0.18 & 0.54 \\
htrAeT & 27 & 143 & 177 & 34 & 158 & 7.69 & 4.62 & -0.34 & 0.17 \\
\hline
\end{tabular}

Table 2. Correlations between the researched marks

\begin{tabular}{|c|c|c|c|c|c|c|c|c|}
\hline & $\mathrm{VO}_{2 \max }$ & $\mathrm{VVO}_{2 \max }$ & vAnT & vAeT & vrdst & htrVO,max & htrAnT & htrAeT \\
\hline $\mathrm{VO}_{2 \max }$ & 1 & 0.52 & 0.15 & -0.11 & 0.15 & -0.83 & -0.61 & -0.59 \\
\hline $\mathrm{VVO}_{2 \max }$ & & 1 & 0.63 & 0.61 & 0.85 & -0.57 & -0.78 & -0.81 \\
\hline vAnT & & & 1 & & 0.63 & -0.21 & -0.24 & -0.28 \\
\hline vAeT & & & & 1 & 0.79 & 0.11 & 0.14 & 0.21 \\
\hline vrdst & & & & & 1 & -0.14 & -0.31 & -0.35 \\
\hline htrVO,max & & & & & & 1 & 0.79 & 0.82 \\
\hline htrAnT & & & & & & & 1 & 0.61 \\
\hline htrAeT & & & & & & & & 1 \\
\hline
\end{tabular}

Figure 1 shows the dynamics of the test results for $\mathrm{VO}_{2}$ max in running with the progressive increase in speed. It is clear that it is extremely dependent on the individual qualities of the different competitors. At the same time, the theoretical trend is described by a parabolic dependence that follows the logical trend of increase in the intensity and the amount of oxygen required for the muscle energy supply.

$\mathrm{VO}_{2} \mathrm{max} / \mathrm{kg}$ shows the importance of body weight in determining the exact amount of oxygen that the body absorbs in the energy supply of a motor activity. The data from this analysis are presented in Figure 2. Comparing the trends in the graphs (Figure 1 and Figure 2), we see they are much more similar to those describing the dynamics of total oxygen consumption during rest. This confirms the claim that individual body weight has a significant effect on the functional efficiency of energy supply at different speeds. 


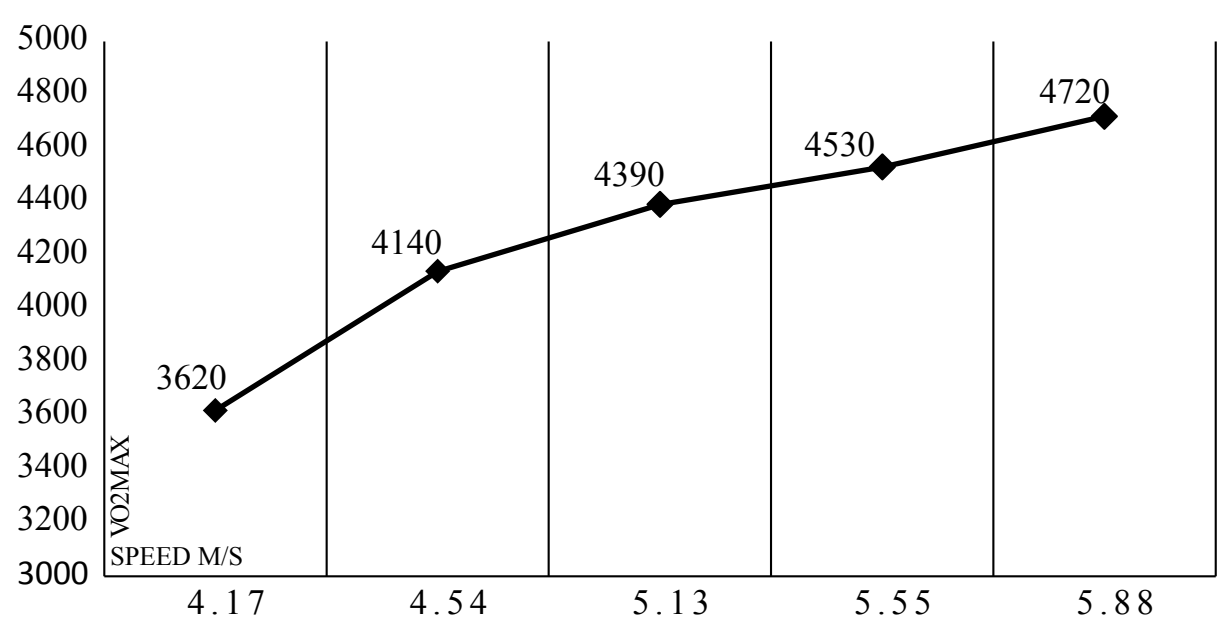

Figure 1. Dependence between $\mathrm{VO}_{2}$ max and speed of running (work and rest).

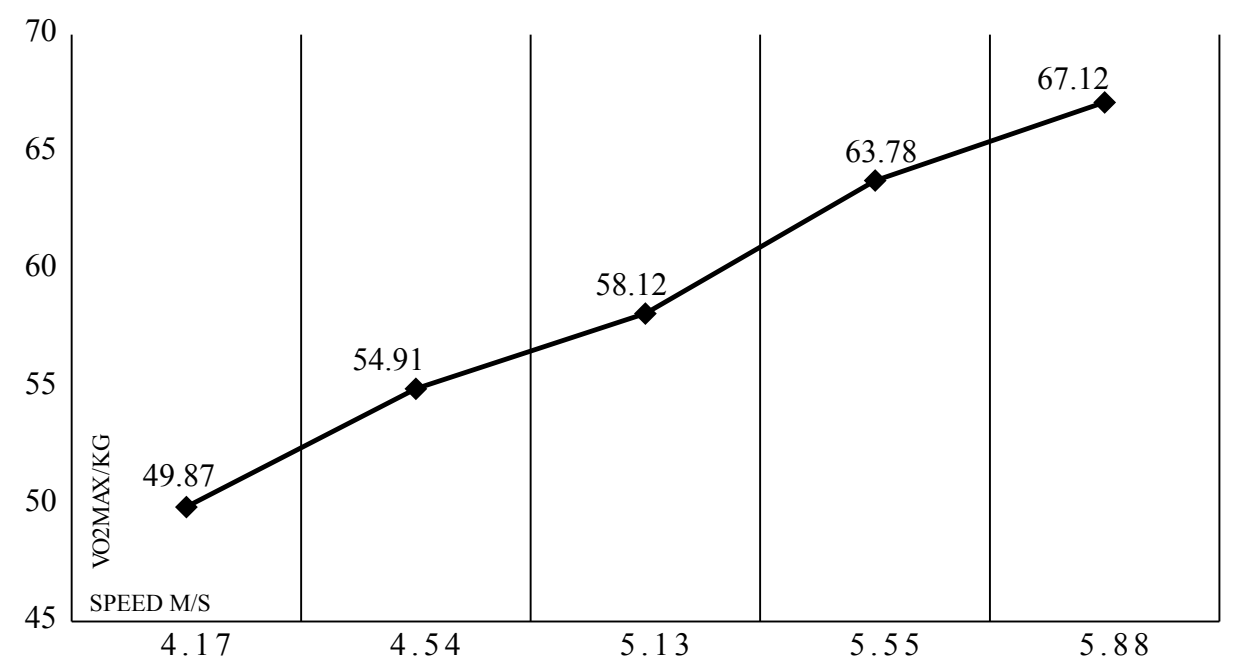

Figure 2. $\mathrm{VO}_{2} \max / \mathrm{kg}$ in work phases.

All this gives us reason to make the following conclusions about the oxygen consumption that determines the quantitative characteristics of adaptation markers of aerobic performance of elite athletes in medium distance running: aerobic threshold $<50 \mathrm{ml} /$ $\mathrm{kg} / \mathrm{min}$; effective aerobic zone $50-55 \mathrm{ml} / \mathrm{kg} /$ $\mathrm{min}$; anaerobic threshold of $55 \mathrm{ml} / \mathrm{kg} / \mathrm{min}$; anaerobic zone $55-65 \mathrm{ml} / \mathrm{kg} / \mathrm{min}$; high acidosis $>65 \mathrm{ml} / \mathrm{kg} / \mathrm{min}$.

Figure 3 presents trends that characterize the dependence between the power of the breathing processes and La in the capillary blood. Comparing the dynamics and the position of these curves, we can outline two "criti- cal" (inflation) points of adaptation changes in the energy metabolism: $2 \mathrm{mmol} / 1$, provided by an oxygen supply of $50 \mathrm{ml} / \mathrm{kg}$ of body weight per minute; $4 \mathrm{mmol} / \mathrm{l}$, provided by an oxygen supply of $58 \mathrm{ml} / \mathrm{kg}$ of body weight.

The presented results establish the following two "thresholds" of the energetic metabolism of physical performance: "aerobic" and "anaerobic". Identifying the intensity of muscle work that provokes transitions from one area to another is basic for functional training not only in middle and long distance runs but also in sport as a whole. The study confirms that the interdependence between the dynamics of metabolic acidosis and the progressive 


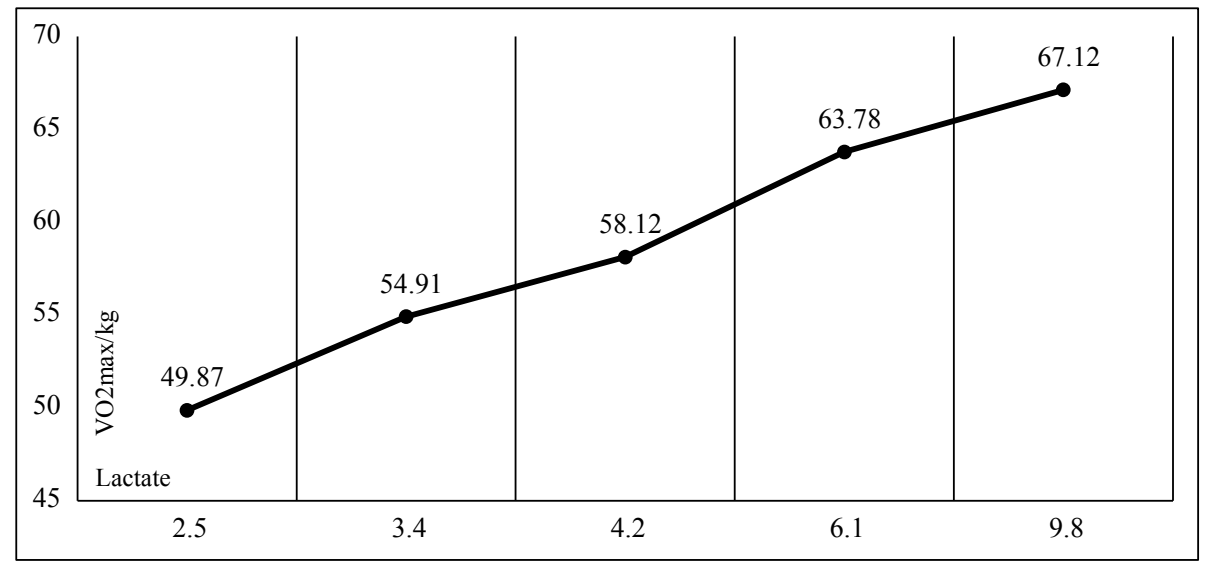

Figure 3. Correlation between $\mathrm{VO}_{2} \max / \mathrm{kg}$ and $\mathrm{La}$.

increase in the intensity of muscular work is exponential.

The adaptive markers defined by this dependence are: Running speed in effective aerobic mode from $4.10 \mathrm{~m} / \mathrm{s}$ to $5.13 \mathrm{~m} / \mathrm{s}$. Continuous running aimed at improving the functionalities should be conducted at a running speed within that range. The values given are valid mainly for competitors with similar results. In addition to the control of the functional effect of the applied running loads, the results from the analysis of the pulse changes in the respective metabolic zones are also provided.

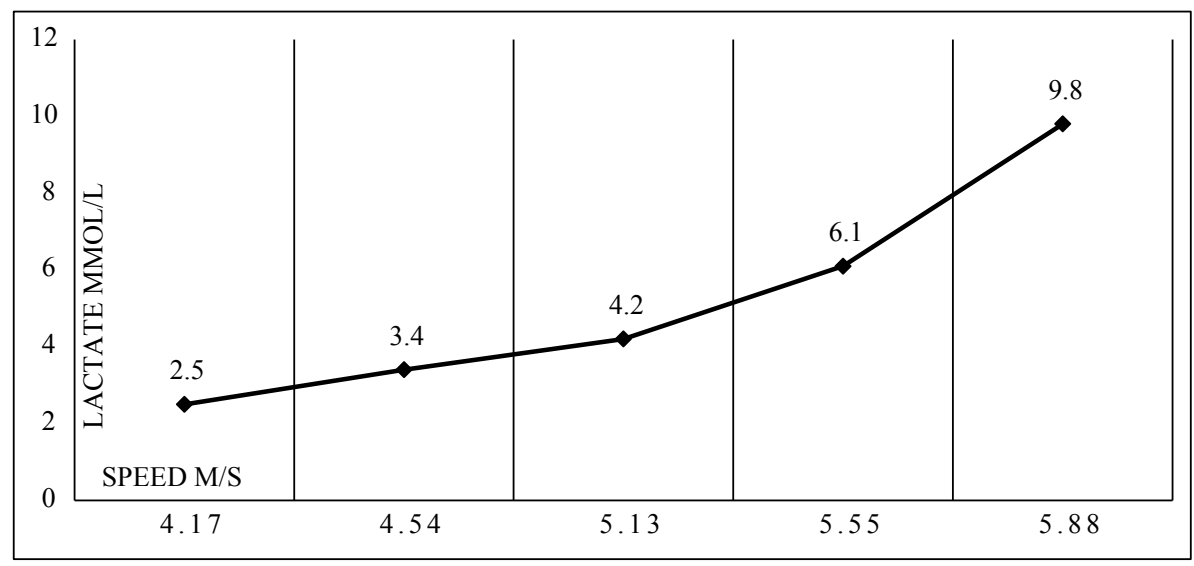

Figure 4. Dependence between running speed and La.

Figure 5 shows the dynamics of metabolic acidosis processes during the load. This dependence repeats the previously described trends defining the quantitative parameters of the respective adaptation markers. The first critical point is $2.2 \mathrm{mmol} / 1$ of lactate associated with a heart rate of 157 beats $/ \mathrm{min}$. The second critical point - $4 \mathrm{mmol} / 1$ lactate at a pulse rate of 178 beats/min. Here, however, we find a third critical point that corresponds to $6 \mathrm{mmol} / \mathrm{l}$. And heart rate 185 beats $/ \mathrm{min}$.

These values complement the information about the effective aerobic work area of muscle work, which in the present case is limited - the pulse ranges from 157 to 178 beats/min. At the same time, one of the most often used indicators of functional properness is the pulse rate dynamics in restorative pauses. 


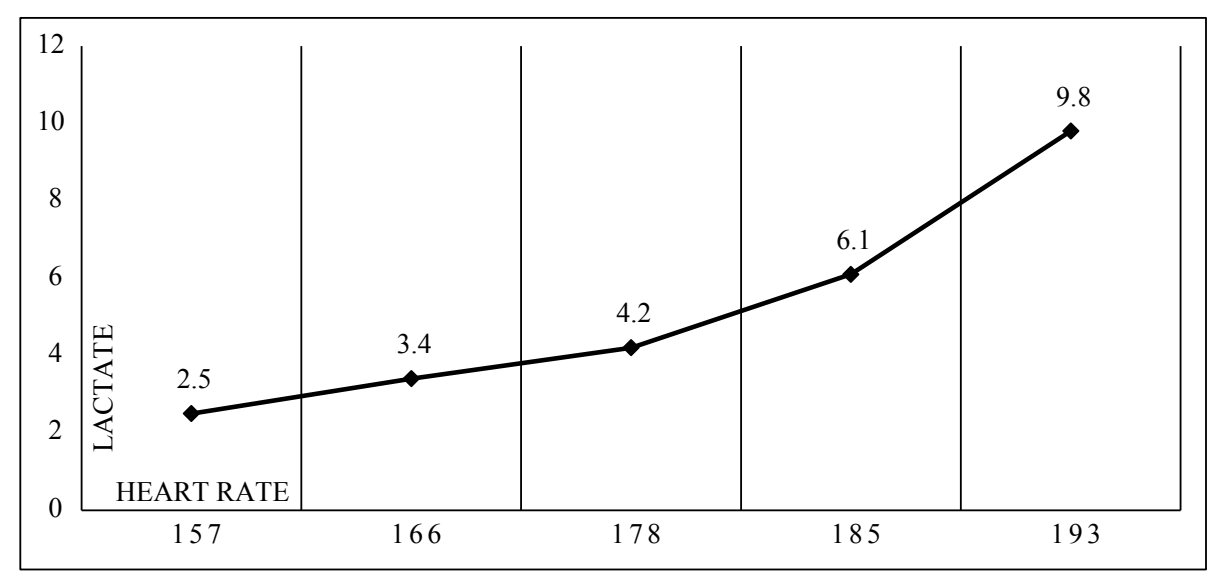

Figure 5. Dependence between heart rate and La.

Figure 6 shows the dependence of the pulse on the lactate accumulation in the rest periods. We see that the areas of low, medium and high intensity are clearly outlined, as well as the quantitative data reflecting the degree of training and adaptability to the applied running loads. This phenomenon is extremely im- portant in the implementation of operational control and regulation of running loads. The quantitative limits of metabolic processes reveal wide possibilities for improvement of the individual exercise training in functional sports.

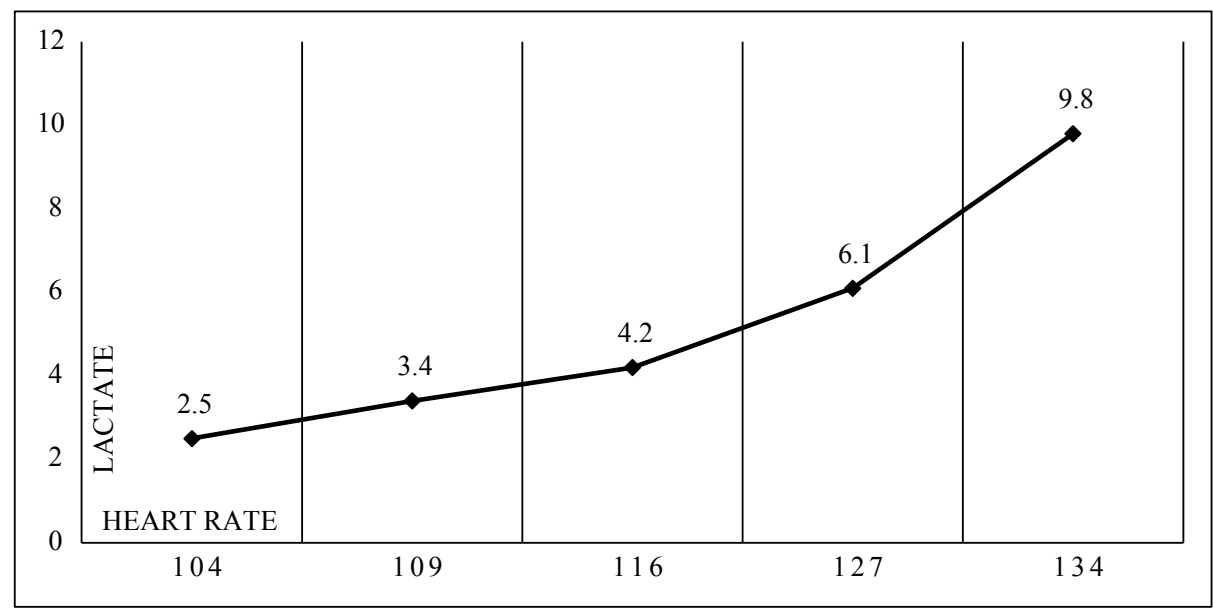

Figure 6. Dependence between heart rate and La in the phases of rest.

\section{CONCLUSIONS}

1. The speed of recovery of the pulse frequency in the phases of the shortened rest is the correct adaptation marker for the determination of the individual tolerance in running loads and athletes' level of training.

2. The recommended quantitative values of the respiratory and metabolic adaptation markers and their associated running speed are as follows:

- aerobic threshold - $2 \mathrm{mmol} / \mathrm{l}$ at a running speed of less than $4.10 \mathrm{~m} / \mathrm{s}$ and a heart rate up to 157 beats/min. (zone stabilizing the capacity of the aerobic metabolic mechanism);

- anaerobic threshold - $4 \mathrm{mmol} / \mathrm{l}$ at a running speed between 4.10 and $5.13 \mathrm{~m} / \mathrm{s}$ and a 
pulse limit of 157-178 beats/min - an effective aerobic zone;

- over 178 beats/min and the running speed over $5.13 \mathrm{~m} / \mathrm{s}$ - a zone developing maximum breathing processes).

3. The pulse frequency in the rest phase characterizes the adaptation processes as follows: unrestricted adaptation from 105 to 115 beats/min; limited adaptation 115-135 beats/min; impaired adaptation over 135 beats $/ \mathrm{min}$.

\section{REFERENCES}

Arrese, A.L., Izquierdo, D.M, Urdiales, D.M. (2005). A review of the maximal oxygen uptake values necessary for different running performance levels. New StudiesinAthletics- volume 20, pp. 7-20.

Astrand, P.O., Rodahl, K. (1986). Textbook of Work Physiology, New York - St. Louis, pp 120-122.

Bassett, D., E. Howley. (2000). Limiting factors for maximum oxygen uptake and determinants of endurance performance, MedSci Sports Exerc, Tennessee, USA;

Bauckaert, J., Vrigens, J., Pauner, J. (1999). Effect Special tests Procedures on Plasma lactate concentration and epoxy oxygen uptake in endurance athletes. The Journal of Sport Medicine and Physical fitness, v.30., pp 12-13.

Bonov, P. (1991). Study of the relationship between speed, hart rate and accumulation of lactic acid in blood mag. New Studies in Athletics, vol.4, IAAF, London.

Bonov, P. (2003). Biagane za izdrajlivost I adaptacia, Sofia, Tip-top pres.

Dasheva, D. (2002). Trenirovka I adaptacia v sporta, Sofia, Bins.

Dick, F. W. (2002). Sports Training Principles, A\&C Black, London.
Furnadjiev, V., Abadjiev, I. (2005). Adaptacia v sporta, Sofia, NSA.

Grancharov, N. (1997). Anaerobniat prag - sushtnost I prilojnastoinost, Dissertation, Sofia, NSA.

Housh, T., Thorland, W., Johnson, G. Tharp, G., Cisar, C. (1984). Anthropometric and body buils variables as discriminators of event participation in elite adolescent male track and field athletes. Journal of Sport Sciences., 2(1), pp. 3-11.

LaTorre, A., Impellizzeri F.M., Dotti A., Arcelli E. (2005). Do caucasian athletes need to resignt hemselves to African domination in middle and long distance running ? New Studiesin Athletics- volume 20, pp. 39-49.

Lazarov, G. (1978). Biagane na sredni razstoiania, Disertation, Sofia, VIF.

Mirzaei, M. R., Shadmehr, M. (2016). Effects of IMT on energy cost in elite endurance runners. New studies in athletics, 1-2, p. 7.

Neikov, S., Dasheva, D. (2017). Planirane I upravlenie na zakliuchitelnia etap na podgotovka za glavni sastezania pri elitni sportisti, "Sport and science" No 1, pp 7-17.

Neumann, G. (1988). Special performance capacity. In: Dirix, A., Knuttgen, H.G. \& Tittel, K. (eds), The Olympic Book of Sports Medicine, Vol. 1. Blackwell \& Scientific Publications, Oxford, pp. 97-108.

Slavchev, A. (1997). Optimal training speed in continuous running efforts in the middle and long distances - Second Annual Congress of the European College of Sport Science, 20-23.08.1997, Copenhagen, Denmark, Poster Presentations, Book of Abstracts II, p.918.

Strydom, N. (1978). The relationship of maximum oxygen intake to gross body mass 
and somatotype. Physical Activity Sciences: H. (2000). Running economy of African and Biomehanics of Sports and Kinanthropom- Caucasian distance runners. Medicine. Scietry, Vol. 6, pp. 571-580. Miami, Florida. ence. Sports Exercise., Vol. 32, No. 6, pp.32.

Weston, A. R., Mbambo, Z., Myburgh, K.

\section{Corresponding author:}

Ivaylo Lazarov

Track and Field athletics department National Sports Academy "Vassil Levski" Studentski grad, 21, Acad. Stefan Mladenov str. Sofia 1700, Bulgaria E-mail: ivolazarov81@gmail.com 